\title{
Acute carpal tunnel syndrome from a foreign body in the carpal tunnel
}

\author{
Chenicheri Balakrishnan MD, Lisa M Bradt RN, Roxanne L Sylora MD, Nirutisai Graff MD
}

C Balakrishnan, LM Bradt, RL Sylora, N Graff. Acute carpal tunnel syndrome from a foreign body in the carpal tunnel. Can J Plast Surg 2002;10(1):42-43.

A case of acute carpal tunnel syndrome as the result of a foreign body in the carpal tunnel is reported. The diagnosis was based on the patient's symptoms and radiographs. Early recognition and decompression of the carpal tunnel with removal of the foreign body led to a full recovery.

Key words: Acute carpal tunnel syndrome
Syndrome aigu du tunnel carpien déclenché par la présence d'un corps étranger

RÉSUMÉ : Le présent rapport porte sur un cas de syndrome aigu du tunnel carpien déclenché par la présence d'un corps étranger. Ce diagnostic a été posé sur la base des symptômes de la patiente et de ses radiographies. La reconnaissance précoce du problème et la décompression du tunnel carpien par extraction du corps étranger ont permis une récupération complète.
$\mathrm{C}$ ompression of the median nerve at the wrist is the most commonly recognized nerve entrapment syndrome. Although various etiologies have been reported for this syndrome, acute carpal tunnel syndrome is rare. Early diagnosis is usually based on the patient's history, clinical signs and radiographs. A search of the literature revealed only one previously reported case of acute carpal tunnel syndrome associated with a foreign body in the carpal tunnel.

\section{CASE PRESENTATION}

An 18-year-old woman presented to the emergency department after her hand went through a glass door. She had two small lacerations over the dorsal aspect of the hand. She had no medical history of any serious illness, no known drug allergies, and she was not taking any medications. She complained of tightness of the hand and tingling of the fingers. There were limited active movements of the fingers, and passive extensions of the fingers were painful. An initial examination showed slight swelling of the wrist, with two puncture wounds over the radial side of the dorsum of the hand (Figure 1). There was paresthesia of the median nerve distribution. The two-point discrimination was prolonged on the injured side compared with the other side, and Tinel's test was positive. Although there were no injuries to the palm or forearm, a clinical diagnosis of acute carpal tunnel syndrome was made based on clinical signs. 


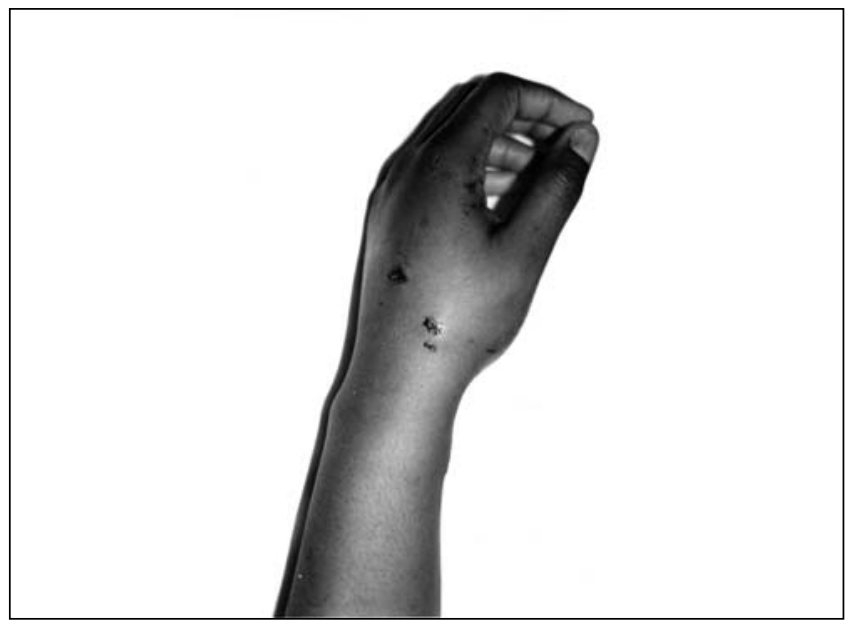

Figure 1) Penetrating wound of the dorsum of the hand

Radiographic studies of the wrist revealed a foreign body in the palmar side of the hand (Figure 2). The decision was made to decompress the carpal tunnel and remove the foreign body. The patient was administered antibiotics and her wrist was splinted to prevent migration of the glass into the median nerve. At the time of exploration, blood and a piece of glass were found within the carpal tunnel. The median nerve showed no evidence of injury. Decompression of the carpal tunnel with removal of the foreign body relieved the symptoms.

\section{DISCUSSION}

Various conditions are associated with carpal tunnel syndrome - the compression of the median nerve at the wrist. Fracture around the wrist is the most common etiology for acute carpal tunnel syndrome. Phalen (1) contributed much to the present understanding of the etiology, diagnosis and management of this syndrome. Other etiologies for carpal tunnel syndrome include acute pyogenic infection, spontaneous hemorrhage in patients who take anticoagulants, thrombosis of a persistent median artery and pseudogout $(2-8)$. When interstitial pressure in the intracarpal canal rises above a critical threshold, capillary blood flow is

\section{REFERENCES}

1. Phalen GS. The carpal tunnel syndrome. Seventeen years' experience in diagnosis and treatment of six hundred fifty-four hands. J Bone Joint Surg 1966;48:211-28.

2. Mack GR, McPherson SA, Lutz RB. Acute median neuropathy after wrist trauma. The role of emergent carpal tunnel release. Clin Orthop 1994;300:141-6.

3. Lynch AC, Lipscomb PR. The carpal tunnel syndrome and Colle's fractures. JAMA 1963;185:363-6.

4. Gaur SC, Kulshreshtha K, Swarup S. Acute carpal tunnel syndrome in Hansen's disease. J Hand Surg 1994;19:286-7.

5. Ogilvie C, Kay NR. Fulminating carpal tunnel syndrome due to gout. J Hand Surg 1988;13:42-3.

6. Chiu KY, Ng WF, Wong WB, Choi CH, Chow SP.
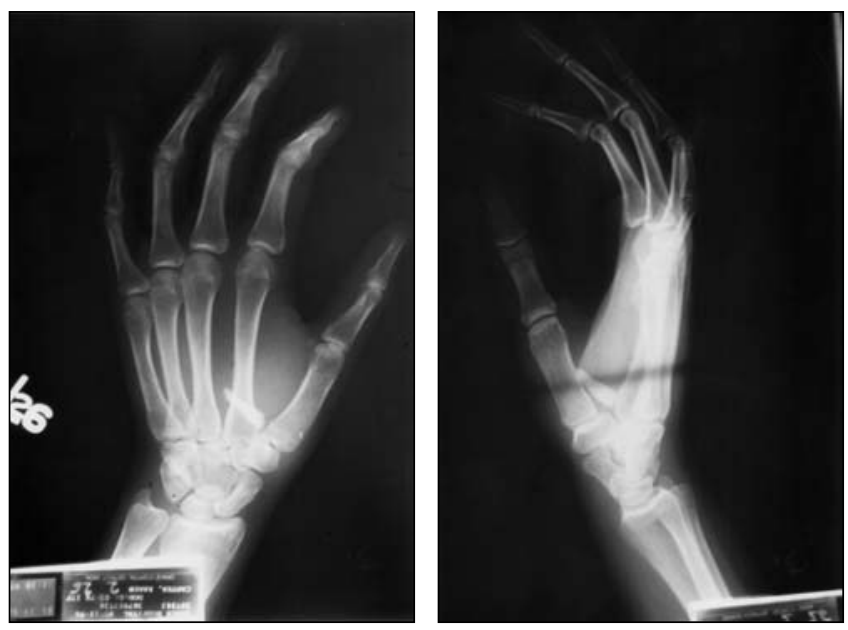

Figure 2) Radiographs showing a foreign body within the carpal tunnel

reduced below the level that is required for median nerve viability. This condition warrants prompt recognition and treatment (9). In acute peripheral nerve compression, preoperative electrodiagnostic examination is usually recommended to confirm the diagnosis. If atypical nerve compression is suspected, magnetic resonance imaging may be indicated to detect the localized nerve compression and its underlying cause (10). This patient's main symptoms were a sudden onset of numbness in the median nerve distribution and pain in the fingers. Because there was a puncture wound and a foreign body was located by the radiograph, no electrodiagnostic studies were performed.

Anatomically, the carpal tunnel has bony walls, except for the volar side. Usual injures to structures in this space occur when the volar skin is injured. In this patient, the foreign body entered the carpal tunnel through the dorsum of the hand. The symptoms of acute carpal tunnel syndrome developed as a result of pressure from the foreign body and bleeding into the carpal tunnel. This emphasizes the need for radiological examination for all penetrating hand wounds and vigilance in the diagnosis of carpal tunnel syndrome. Early decompression with removal of the foreign body was associated with a full recovery.

Acute carpal tunnel syndrome caused by pseudogout

J Hand Surg 1992;17:299-302.

7. Bonatz E, Seabol KE. Acute carpal tunnel syndrome in a patient taking Coumadin: case report. J Trauma 1993;35:143-4.

8. Balakrishnan C, Smith MF, Puri P. Acute carpal tunnel syndrome from thrombosed persistent median artery. J Emerg Med 1999; 17:437-9.

9. Szabo RM. Acute carpal tunnel syndrome. Hand Clin 1998;14:419-29.

10. Sterling AP, Eshraghi A, Anderson WJ, Habermann ET. Acute carpal tunnel syndrome secondary to a foreign body within the median nerve. Bull Hosp Joint Dis 1972;33:130-4. 